\title{
LA CARACTERIZACIÓN DE LAS PRÁCTICAS DE JUSTICIA PENAL DE LAS ACTUALES COMUNIDADES INDÍGENAS EN EL DEPARTAMENTO DEL HUILA
}

Semillero de Investigación adscrito al grupo de investicación SINERGYA (Categoría C Colciencias) de la Facultad de Derecho de la Universidad Surcolombiana.

SEMILLERO INTI YACTA

INTEGR ANTES

Adriana Constanza Obando, Omar Ciceri Pizo, Omar Hernando Narváez, Natalia Bustamante García, Gloria Isabel Gaitán Trujillo, Jorge Horacio Guzmán, Cristian Camilo Rojas, Cristian Camilo Lugo, Marco Useche Bernate, Pedro Andrés López, Lida Yazmín Cepeda, Juan Carlos Olarte, Melba Luz Cuenca Almario, Ivan Dario Gutiérrez, Laura Liliana Castillo, Mayra Alejandra Charry, Mónica Molina Leytón, Yuri Shirley Saldarriaga, Jesús Alberto Manios.

Docente Tutor: Mg. Martha Cecilia Abella de Fierro.

\section{Resumen}

En el contexto del Estado Social de Derecho es necesario responder a las necesidades concretas de la diversidad y heterogeneidad de las demandas de los grupos poblacionales de Colombia, para comprender su naturaleza y nivel de coherencia con el ordenamiento jurídico. La pertinencia temática de las jurisdicciones, sistemas o justicias especiales, como el caso de la indígena y específicamente en el Departamento del Huila, obedece a la incertidumbre frente a su problemática, condiciones de vida, procesos de desarrollo, costumbres y cultura, cuando en virtud de su autonomía desarrollan prácticas de justicia nativa de las que no se tiene idea de sus aplicaciones penales, la tipicidad de los delitos, las sanciones, las penas, y los conflictos que tienen este tipo de prácticas tanto al interior de la comunidad como con la justicia ordinaria.

\section{Palabras Clave}

Jurisdicción Especial Indígena, caracterización de las prácticas penales Indígenas, delitos, tipicidad, penas, sanciones, Comunidades Indígenas en el Huila.

\section{Abstract}

In the context of the Social State of Right is necessary to respond to the specific necessities of the diversity and heterogeneity of the demands of the populational groups of Colombia, to understand their nature and level of coherence with the juridical order. The thematic relevancy of the jurisdictions, systems or special justice, ace the marries of the indigenous and specifically in the Department of the Huila, it obeys the uncertainty in front of their problem, conditions of life, 
development processes, custom and culture, when by virtue of their autonomy it develops practical of native justice of those that one doesn't have devises of their penal applications, the prescription of the crimes, the sanctions, the hardships, and the conflicts that have this so much type of practices to the interior of the community like with the ordinary justice.

\section{KEYS WORDS}

Indigenous Special jurisdiction, characterization of the Indigenous penal practices, crimes, prescription, hardships, sanctions, Indigenous Communities in the Huila.

\section{INTRODUCCIÓN}

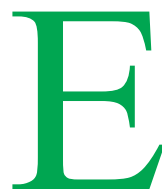

$\mathrm{n}$ mérito del resultado de una sistemática y seria investigación desarrollada por el semillero INTI YACTA -"TIERRA DEL SOL"conformado por estudiantes de la Facultad de Derecho de la Universidad Surcolombiana, relacionada con el tema de los conflictos de competencia suscitados entre la Jurisdicción Ordinaria y la Jurisdicción Especial Indígena en cuanto a sus prácticas penales, se estructuró una metodología de trabajo, teniendo en cuenta el origen o la llegada al Departamento del Huila de las comunidades indígenas GUAMBIANA, YANACONA, NASA- PÁEZ, TAMA y PIJAO, con el objetivo principal de caracterizar el desarrollo y vivencia de los mencionados grupos poblacionales en el Departamento del Huila, estableciendo especialmente la pertinencia, eficacia y efectividad de su fuero, profundizando fundamentalmente en la concretización del Estado Social de Derecho y aportando para la construcción de un conocimiento viable que pudiere servir a su vez en la materialización de la justicia en casos y circunstancias específicas de la diversidad y heterogeneidad nacional.

La constitución de los asentamientos indígenas en el departamento ha generado confusión. No obstante, este es un tema novedoso para las instituciones y la población en general, en razón a que existe a la vez desconocimiento sobre su historia y características culturales, problemas $\mathrm{y}$ conflictos de supervivencia $\mathrm{y}$, ante todo, incomprensión del fuero especial que los faculta a tener un sistema de justicia propio, elemento central que permite y constituye el desarrollo integral de su autonomía, modos, usos y costumbres de la población nativa. A partir de esa soberanía especial, la reflexión que se suscita, gira en torno a las relaciones del Estado colombiano con sus ciudadanos, fundamentalmente con las minorías étnicas que, como en muchos casos, se presenta con frecuencia en contradicciones sociales que agudizan el desconocimiento de los principios fundamentales que se pregonan constitucionalmente y ante la ausencia de una articulación entre la jurisdicción especial indígena y el sistema judicial ordinario o administración de justicia.

Es necesario reconocer que el nivel de obtención de la información no fue siempre el esperado, dado que las autoridades indígenas de las comunidades visitadas, no permitieron nunca y en ningún caso, el acceso directo a sus archivos, actas y documentos propios de sus asambleas que desarrollan asuntos de justicia nativa, con lo cual, la información fue únicamente obtenida a través de las entrevistas y por tanto, derivadas de lo que a su juicio los directivos indígenas quisieron manifestar.

Escomprensiblequelos pueblosnativostenganuna contundente actitud defensiva y de desconfianza frente a los "blancos" y que por tanto mantengan en reserva sus conflictos y problemas internos, dado que no siempre la información que se obtiene puede ser utilizada de la mejor forma, $y$ en algunos casos, según ellos, no genera beneficios para la supervivencia de sus comunidades. Sin 
embargo, debemos agradecer la amabilidad de las comunidades Nasas, Guambianas, Yanaconas y Tamas, quienes nos recibieron cordialmente, nos brindaron hospedaje, compartieron sus alimentos típicos, sus muestras y manifestaciones culturales y en lo que consideraron pertinente, información frente a sus prácticas penales.

Es evidente que existen al interior de las comunidades indígenas serios problemas que agravan su situación, como es el bajo nivel de organización, pérdida parcial de elementos de identidad, desconocimiento de la legislación indígena, adolecidos con el creciente marginamiento de sus sistemas productivos, debido a que no cuentan con proyectos que garanticen la protección adecuada a su nivel de vida. Este fenómeno de aculturación es totalmente entendible, desde el punto de vista de los diferentes procesos migratorios a los que se han visto sometidos y que han traído consigo consecuencias como el mestizaje, luchas intensas por la recuperación de tierras, pérdida de muchos de sus integrantes por cuenta de desastres naturales, desplazamiento por causa del conflicto armado, circunstancias estas que han originado la fragmentación de los grupos y el desvanecimiento de su cosmovisión.

La necesidad de la presente investigación radicó en que no existía una unidad documental sistematizada de las diversas investigaciones que se han desarrollado en relación con los pueblos aborígenes en el Huila, y con las prácticas penales desde la jurisdicción especial indígena. No se conoce con objetividad si las comunidades indígenas que habitan el Huila, desarrollan plenamente la aplicación de la justicia especial, no se conocen sus prácticas penales, la tipicidad de los delitos, las sanciones y las penas; de igual forma, qué clases de conflictos tienen estas experiencias al interior de las comunidades.

LOS PROCESOS DE POBLAMIENTO DE LAS ACTUALES COMUNIDADES INDÍGENAS DEL HUILA ${ }^{1}$. MIGRACIÓN EN BÚSQUEDA DE TERRITORIOS.

Los grupos indígenas del país, tuvieron que soportar toda la devastación del dominio español el cual, poco a poco fue permeando su forma de vida y sus costumbres. Después del proceso de conquista, la mayoría de los grupos se asentaron en el departamento del Cauca ${ }^{2}$, pero a raíz de la avalancha del río Páez ocurrida el 6 de junio de 1994, éstas comunidades se vieron obligadas a realizar un abrupto proceso migratorio hacia otros lugares del país. Es precisamente en este punto en donde podemos encontrar en gran medida la génesis de las comunidades indígenas que habitan hoy en día el Departamento del Huila, debido a que con la avalancha del río Páez, se crea por parte del Gobierno la Corporación NASAKIWE en pro de la reubicación y el apoyo a los damnificados con el desastre natural ${ }^{3}$.

Desde inicios del siglo XX, también se vienen presentando con frecuencia migraciones de indígenas provenientes del Cauca, que llegaban al Huila motivados por diferentes aspectos tales como la sobrepoblación, la búsqueda de trabajo, recuperación de territorios ancestrales y ante todo de tierras para vivir. Dichos desplazamientos fueron realizados a nivel individual o familiar, pero no como organización o proyecto de población a nivel de un resguardo. ${ }^{4}$ Tanto así, que estas poblaciones étnicas permanecieron en el Huila trabajando como jornaleros, partijeros, arrendatarios y realizando todo tipo de trabajos en el campo. Posteriormente, algunos con mucho esfuerzo lograron comprar pequeñas fincas y con el tiempo fueron trayendo más familiares hasta

1 Gran parte de la información referida en este capitulo, es el fruto de la combinación con el trabajo publicado por el Coordinador del proyecto-Dr. Nelson Darío Rincón García- especialmente al articulo sobre la historia de las actuales comunidades indígenas del Huila, que se encuentra en el Vol. VI de la Historia General del Huila y los aportes de los estudiantes del Semillero Inti Yacta.

2 Mayor información sobre la Comunidad Nasa Páez del Departamento del Cauca en el libro GEOGRAFÍA HUMANA DE COLOMBIA -REGION ANDINA CENTRAL-; Tomo IV-volumen 2; Instituto Colombiano de Cultura Hispánica, “Los Nasa o la Gente Páez” pág. 87.

3 La Corporación NASAKIWE fue creada mediante Decreto extraordinario 1179 del 9 de junio de 1994.

4 Todas las afirmaciones, son tomadas a partir de diversas entrevistas a los miembros de las distintas comunidades. Para mayor credibilidad, se poseen cassettes, videos y fotografías que pueden constatarlo. 
llegar a ser uno de los mayores componentes de la población rural de estos municipios.

Durante más de ochenta años permanecieron en el anonimato como indígenas hasta 1991, cuando comienzan a la luz de la Carta Política sus procesos de organización.

Empero, los efectos del tiempo contaminaron su arraigo cultural afectando en gran medida sus costumbres; muchos de ellos terminaron occidentalizados y viviendo como campesinos dedicados al agro y al cuidado de animales, adquiriendo propiedad privada y satisfaciendo sus propios intereses. Otros, que aún conservan algunos de sus hábitos, vestuario, lenguas nativas y prácticas, también se apropiaron de algunas instituciones que con la conquista trajeron los españoles, cuyo caso más particular es el del Cabildo.

Los procesos de organización han permitido además, la reclamación de legalización de tierras ante el Estado colombiano por parte de personas inescrupulosas y oportunistas que agrupándose para terminar autodenominándose descendientes de diferentes grupos aborígenes, y los que hasta con el uso de la violencia se han hecho acreedores de las prerrogativas de las cuales, otras poblaciones realmente nativas han sido despojadas sin haberlas podido disfrutar.

Como características básicas de cada comunidad es propicio aclarar que para ubicar al lector de éste artículo dentro de un contexto espacial y temporal -aunque éste no es el tema fundamental del trabajo de investigación realizado, pero el que de manera más profunda y detallada se relaciona en uno de los capítulos del documento final elaborado- tangencialmente se exponen de forma breve a continuación, para dar paso a aquello que realmente nos convoca LA CARACTERIZACIÓN -GENERAL- DE LAS PRÁCTICAS DE JUSTICIA PENAL DE LAS ACTUALES COMUNIDADES INDÍGENAS EN EL DEPARTAMENTO DEL HUILA.

\section{Comunidad de los Guambianos}

La migración de ésta comunidad se origina porque las familias al tener numerosos hijos en las fincas que poseían, no tenían la suficiente cantidad de tierra para repartirla con los hijos, dado que cuando se casan $\mathrm{y}$ crean nuevos núcleos familiares, necesitan construir sus viviendas y a la vez sus parcelas de producción, tanto agrícola como ganadera. Los indígenas culturalmente son tierra, y por ello ante los incipientes hogares, requieren de nuevos dominios para posibilitar el desarrollo familiar. Éste pueblo indígena está conformado por cuatro importantes resguardos:

\section{La Gaitana:}

Su distribución lo posiciona como el resguardo más grande del Huila incorporando las siguientes veredas bajo su circunscripción:

-El Rosal $\quad$-San Mateo

-Bajo Rosal -El Líbano

\section{Nuevo Amanecer 'La Meseta":}

Ubicada en siete (7) predios, localizados en la jurisdicción del Municipio de La Argentina, Departamento del Huila.

\section{Nam Misak:}

Se encuentra asentada en la vereda El Congreso del corregimiento de Belén municipio de La Plata y las veredas Marsella y Buenos Aires en el municipio de La Argentina, al sur del departamento del Huila, en un área de 846 hectáreas.

\section{La Reforma:}

Se encuentra ubicado en la Inspección de Belén del municipio de la Plata. 


\section{Comunidad de los Yanaconas}

El pueblo Yanacona por lo general perdió parte de los elementos de su identidad por ejemplo no poseen lengua propia, ellos tratan de identificar su origen lingüístico con el Quechua porque poseen en su memoria algunas palabras similares a esta importante lengua de origen Inca; por otro lado, su indumentaria tradicional ya no es usada en la cotidianidad y uno de sus rasgos más característicos es la prevalencia de su identidad y su folclore musical, ya que son expertos en la conformación de los grupos llamados chirimías. Obviamente otro es el proceso de análisis sobre su cosmovisión y desarrollo cultural, que en el presente trabajo no es objeto y no se alcanza a desarrollar. En el momento están trabajando por tratar de reencontrar sus raíces ancestrales. Tales procesos se desarrollan tanto en la población que habita en el departamento del Huila, como los que viven en el Cauca.

Los Yanaconas de Pitalito, Isnos y San Agustín, actualmente están en su mayoría organizados como cabildos indígenas; han desarrollado sus organizaciones y en este momento, dos de sus comunidades poseen terrenos en calidad de Resguardo. Ellas son la Comunidad Yanacona de San Agustín y la comunidad de Palmar de Criollo, Resguardo de "Rumiyaco" de Pitalito, los demás (4 cabildos) continúan trabajando para lograr la adjudicación de terrenos, cuyos procesos los adelanta el INCODER.

\section{Comunidad de los Nasas - Paeces}

El origen de esta comunidad se debe también al producto de la migraciones de indígenas del Cauca, que por razones de búsqueda de tierras y de mejores oportunidades de vida, salieron de sus resguardos y territorios ancestrales, migraron debido a la contratación como jornaleros en distintas fincas hasta que llegaron en el año de
1940, a lo que hoy se conoce como la inspección de San Vicente del Municipio de La Plata, por esa época no se había fundado dicha inspección. ${ }^{5}$ La procedencia de los Paeces se puede examinar bajo dos pautas de análisis; la primera, teniendo en cuenta la comunidad Páez a nivel nacional ( Tierradentro -Huila y Cauca-), y la segunda, siguiendo el proceso migratorio que se llevó a cabo en el Departamento del Huila a raíz, especialmente, de la avalancha del río Páez en el año de 1994.

La comunidad indígena NASA - PÁEZ, se encuentra dividida en ocho resguardos localizados especialmente en la zona sur del Departamento; su medio ecológico fluctúa entre diversos climas y accidentes demográficos y sus características culturales guardan una gran similitud con la comunidad PÁEZ del Departamento del Cauca, ya que, es precisamente en ésta zona donde encontramos el origen de la actual comunidad NASA del Departamento del Huila.

\begin{tabular}{|l|l|l|}
\hline 1. & Palermo - San Francisco & Baché \\
\hline 2. & La Plata - La Estación & La Estación Tálaga \\
\hline 3. & Iquira- Río negro & Huila \\
\hline 4. & La Argentina- Buenos Aires & Pickwe ikh \\
\hline 5. & La Plata-Santa Leticia & Juan Tama \\
\hline 6. & La Plata- El Coral & Potreritos \\
\hline 7. & Itaibe-Cauca & Pickwe Tha Fiw \\
\hline 8. & Nátaga-Yarumal & Llano Buco \\
\hline
\end{tabular}

Comunidad de los Tamas - Paeces y Pijaos:

Resguardos de Paniquita y la Gabriela:

Los habitantes de estos dos resguardos afirman ser oriundos del Caguán, quienes a su vez son descendientes de los antiguos habitantes de esta población constituida desde la época Colonial y después ratificada en los procesos de lucha de la independencia frente a los españoles, por Bolívar y Santander.

5 Esta información es el resultado de diversas entrevistas a los sobrevivientes de esta primera migración Nasa quienes actualmente hacen parte del Resguardo La Gaitana. Tomado de grabaciones en vídeo y cassettes, existe también evidencia fotográfica. Archivo Nelson Darío Rincón. 
Con el tiempo este territorio fue pasando a manos de terratenientes que con presiones y engaños, fueron despojando a los indígenas; también participan la policía y las autoridades departamentales (ratificado esto en las afirmaciones del primer Gobernador del Departamento del Huila). En este aspecto es importante resaltar la masacre de los limpios, donde mueren indígenas Nasas y Tamas; allí capturan al famoso líder indígena Quintín Lame, situación relatada en la llamada masacre de los limpios. Desde 1986 algunas familias que compartieron un proceso de lucha y el actual resguardo de Paniquita, se distanciaron de este proceso, debido a diferencias en la concepción de la organización y a diversas disputas internas por el poder, acusándose mutuamente de corrupción. Por tal motivo, deciden iniciar su propia constitución, creando otro cabildo y desarrollando una lucha similar a los de Paniquita, presionando las instituciones estatales para su reconocimiento. Pero sin lugar a dudas, gracias a que ya estaba reconocido un Resguardo en la zona del Cagúan, esto facilitó que en 1994, después de los procesos de estudio para su reconocimiento por parte del INCORA, se les adjudicara la hacienda llamada la Gabriela, antigua posesión de terratenientes de la zona.

\section{Resguardo Bache Páez de Palermo:}

Localizado en la Vereda San Francisco del Municipio de Palermo. Algunas personas oriundas del Municipio de Palermo, que hasta el momento habían vivido como campesinos, desempeñándose como jornaleros en las veredas del Municipio, algunos con familiares ya en el pueblo y que vivían trabajando en las casas o haciendo cualquier tipo de oficio; ante las condiciones de pobreza se inquietan por formas organizativas, buscando solución a sus condiciones de vida, es así que en el año 1987, se relacionan con la ANUC, Asociación Nacional de Usuarios Campesinos, con esta organización comienzan a trabajar y a tener experiencias formativas; en una asociación se reúnen con ONIC, Organización Nacional Indígena de Colombia, allí conocen de la existencia del entonces Cabildo indígena del Cagúan Dujos, hoy Paniquita.

\section{Resguardo La Tatacoa (etnia Pijao):}

Desde el año 1987, en el casco urbano, de la inspección de La Victoria Vereda San Nicolás, Municipio de Villavieja, se comienzan a reunir varios habitantes, que presionados por su situación económica, de ser jornaleros, arrendatarios, sin territorio y viviendo en la pobreza; deciden comenzar a organizarse para conseguir la tierra a través de una forma comunitaria; en ese sentido visitan las comunidades indígenas de Natagaima, y desde allí toman la idea de recuperar su antepasado indígena.

\section{LA CARACTERIZACIÓN -GENERAL-DE LAS PRÁCTICAS DE JUSTICIA PENAL DE LAS ACTUALES COMUNIDADES INDÍGENAS EN EL DEPARTAMENTO DEL HUILA.}

Por normas y métodos de control social según la cosmovisión ndigena se debe entender: las primeras son las reglas propias de la tradición cultural de cada pueblo indígena, los diversos aspectos de la vida cultural, económica, social y familiar; por las segundas se consideran, formas mediante las cuales las sociedades regulan la conducta de sus miembros, para que cumpla con las reglas y respeten los límites. ${ }^{6}$

En primera instancia, hablamos de ideario de comportamientos, muy similares, porque valga la precisión esencial para la comprensión de este estudio, debemos afirmar que las comunidades indígenas en general, no poseen y no les es necesario tener las normas prescritas, "en un papel", esto les resulta indiferente. La tradición oral de generación en generación, se constituye como la

6 Material suministrado por el Consejo Regional Indígena del Huila. Plan de vida. La Plata Huila. 
mejor herramienta que consolida los lazos de unión entre los comuneros. Así, ante la pregunta, un poco inocente de: ¿Dónde se encuentran compiladas sus normas?, una sencilla respuesta: "cada individuo es un reproductor de esas leyes preexistentes que el humano ha capturado para regirse".

En segunda instancia, la concepción y a la vez razón del correctivo (sanción), muestra claramente una tensión entre dos tipos de pensamiento: el de la sociedad mayoritaria y el de las comunidades indígenas. En la primera, se castiga porque se cometió un delito, en la segunda se corrige para restablecer el orden de la naturaleza y para disuadir a la comunidad de cometer faltas en el futuro. Aquella, rechaza las penas corporales por atentar contra la dignidad del hombre; ésta, las considera como un elemento purificador, necesario para que el mismo sujeto, a quien se le imputa la falta, se sienta liberado.

El cometer una falta, o quebrantar una norma interna, aparta al indígena de los principios de armonía y equilibrio que rigen el mundo natural y social y de los cuales eran derivados los preceptos de convivencia establecidos por los ancestros. La infracción de estas regulaciones rompe el principio de la justicia y se considera que el transgresor se ha torcido o desviado del buen camino.

La tradición legal del sistema carcelario nacional, con su discriminación a los indígenas basada en la consideración de éstos como inimputables, y a lo sumo con su reconocimiento de la peritación antropológica, condujo en muchos casos a la impunidad, y a su vez produjo actitudes pragmáticas de las autoridades indígenas frente al hecho cumplido de la inoperancia de la justicia, como único control social posible dentro de sus comunidades. $^{7}$

Es por ello importante registrar que la etnia, a pesar de no tener prescritos los delitos para las conductas ni mucho menos un procedimiento técnico acompañado de un metalenguaje ni mucho menos de unos términos de preclusión, caducidad y prescripción, ante una situación particular que afecte a la comunidad, siempre a través de sus instituciones y autoridades tomará una decisión en el momento de su ocurrencia, que sirva como escarmiento y genere una conciencia para la colectividad autóctona, en caso de presentarse nuevamente en un futuro, una situación similar o mucho más grave.

\section{De la clasificación de los delitos y las penas:}

Dentro de las prácticas penales y a partir de una inferencia en la que se ha identificado una graduación de las conductas se han podido observar y clasificar:

* Delitos graves: Como el homicidio, infidelidad y el hurto.

* Delitos leves: Peleas callejeras o en fiestas y problemas familiares.

* Otros: Chismes y groserías.

\section{De las sanciones o correctivos:}

Los correctivos que se implementan van desde los corporales o físicos, que son materializados en el fuete o látigo. También hay otros que se dan por ejemplo exhibiendo a la persona que cometió un mal ante la comunidad, para que digan:

"mire él hizo este mal y por lo tanto estamos imponiéndole un correctivo para que no vuelva a cometerlo". Además, porque es un aviso a la colectividad frente a aquello que les podría pasar, para que la comunidad también identifique lo que se está sancionando.

- Trabajo comunitario: Es el más aplicado ya que se requiere de productividad de la tierra, por ende se limpia, se ara y se cultiva con mayor intensidad por quienes reciben tal sanción. 
- Las indemnizaciones a las personas o familias de los afectados: Es un resarcimiento del daño causado, que se realiza en trabajo o especie.

- Crítica: Es una forma de repudiar los actos o conductas cometidos por el indígena infractor de la ley indígena. Es un correctivo conforme al comportamiento del individuo que amerita el rechazo a una conducta desviada, que se acompaña generalmente de advertencias por parte de la comunidad, verbigracia, maltrato entre esposos, infidelidad, falso testimonio etc.

- Regaño: Es algo similar a la crítica, pero se aplica a pequeños casos contravencionales, como el comportamiento de menores en los eventos de "chismes" o como dicen popularmente estas comunidades "inventos", que afectan de alguna manera las relaciones interpersonales de personas o familias, miembros de las etnias.

- Exposición Pública: Consiste en la presentación del acusado, ante toda la comunidad indígena por su mala conducta. Este castigo se utiliza en los casos de peculado por apropiación o por desviación, por parte de los gobernadores, alcaldes o tesoreros de los recursos económicos del resguardo. También se aplica para los casos de abuso de autoridad y hurto.

- El fuete o juete: Antes era un látigo hoy es un lazo de cuero. Posee unos nudos en la punta llamados arrobas, cuyo objeto es causar mayor dolor al azotar. Consiste en la flagelación corporal con un "perrero de arriar ganado", aun tratándose de una práctica heredada de los españoles, tiene un significado propio, el del rayo, que es pensado por los aborígenes como mediador entre lo claro y lo oscuro, es decir, como un elemento purificador.

- El cepo: Instrumento de origen colonial, el cual consiste en colgar a una persona de los pies porque ha cometido un delito como el de homicidio. Actualmente no es muy utilizado por esta comunidad por la crueldad que representa.

- Prisión: Consiste en la detención del implicado en un lugar estrecho, incómodo adecuado por la comunidad y en ocasiones sin alimentación. Se utiliza en algunas oportunidades de manera preventiva mientras se resuelve el caso y en otras para obtener algún tipo de confesión. No todas las etnias lo implementan.

- El destierro: Es el castigo más grave, y sólo se aplica a quienes reinciden en la falta y a los que no aceptan la autoridad del cabildo. Significaría despojarlo de su tierra, su familia y sus costumbres. Igualmente, no todas las comunidades lo implementan.

- Se tienen conductas irregulares no sancionables, dentro de las que se encuentran -como mencionamos- la brujería, por falta de pruebas. Por otro lado, si se presenta que un miembro del resguardo asesina por fuera de este a otra persona, puede corresponder a la jurisdicción ordinaria conocer del caso. $\mathrm{Si}$ por ejemplo robase por fuera, es factible que sea sancionado por su jurisdicción (según la LEY DE COMPETENCIAS -que más adelante se explica-).

\section{DEL PROCEDIMIENTO PENAL: ${ }^{9}$}

La conciencia de pertenecer a una comunidad diferente, aquella en que los miembros tienen de su especificidad que debe ser conservada como tal, ha sido el motor que los ha impulsado a erigir y recuperar sus instituciones sociales, políticas y

9. Asesoría del CRIHU y descripción de los taitas del resguardo Nam Misak. 
jurídicas que, no obstante haber sido influenciadas por la sociedad occidental, no han abandonado aún ciertos aspectos que conservan todavía como auténticos. Un ejemplo de ello es su ordenamiento jurídico, claramente impregnado por simbologías y procedimientos propios.

En lo que respecta a sus prácticas penales, se basan en la costumbre únicamente. Para que pueda iniciarse un proceso, los familiares o el segmento social al que pertenece el afectado deben solicitar al Cabildo o esté debe "enterarse" para adelantar la investigación y sancionar a los culpables. El Cabildo, a su vez, deberá nombrar una comisión investigadora, integrada por personas de prestigio en la comunidad, quienes se encargaran de determinar las faltas y "encontrar la mentira en la palabra de los acusados".

Lo primero que deberá hacer esta comisión investigadora, es citar a los presuntos autores. $\mathrm{Si}$ los citados por el cabildo no acuden al llamamiento, los alguaciles proceden a buscarlos para hacerlos comparecer para que rindan su versión. Si ellos aceptan la responsabilidad, no habrá lugar a otras etapas. Si la niegan, continúa la investigación, recogiendo los testimonios de las personas que dicen haber visto o escuchado algo relacionado con el caso, y realizando las visitas a los lugares donde presuntamente ocurrieron los hechos.

Cumplidos estos procedimientos, el siguiente paso será, entonces, la valoración que hace el Cabildo del informe presentado por la comisión investigadora. Si se encontró la mentira, se cita a una Asamblea General, que como máxima autoridad deberá fallar. Si hay necesidad de convocar al Consejo de taitas (reunión de personas mayores, especialmente hombres, cuya intervención en decisiones trascendentales para la comunidad son tenidas en cuenta como algo de mucho respeto, ya que estos miembros representan ante sus similares, la experiencia, ejemplo, sabiduría y la justicia) dependiendo de la gravedad del asunto, se reúnen los ex gobernadores, quienes conforman tal consejo, en aras de la toma de determinaciones trascendentales para el caso en cuestión, y si lo amerita, imponer las sanciones. En dicha Asamblea se dan a conocer las pruebas y se solicita la confesión pública del acusado. Luego, se realiza un careo mediante un ritual conocido con el nombre de cruce de bastones.

Respecto al debido proceso ${ }^{10}$, en ejercicio del derecho a la defensa se proporcionan los medios en los casos que adelantan las autoridades indígenas para que el acusado pueda ser defendido por un miembro que conozca la lengua y las costumbres y además, tiene la oportunidad de hablar por sí mismo durante la Asamblea, para contradecir a los testigos que declararon en su contra.

Como la Asamblea General es "infalible" según sus miembros, porque consideran que sus decisiones están basadas en la memoria, que se encuentra a través de un ejercicio colectivo que permite hacer público el suceso oscuro, no está contemplada la segunda instancia. Es claro que estos sucesos oscuros no sólo son aquellos que produjeron directamente el daño, sino también los que de alguna manera hayan permitido o facilitado la alteración de la armonía.

Aunque la imputación de la sanción es personal, existen casos en que se extiende a la familia, por no haber contribuido a detener la infracción. Tal situación se explica porque, en la tradición aborigen, una de las responsabilidades principales del núcleo familiar es conocer o controlar lo que hace cada uno de sus miembros. Generalmente debería llevarse un acta o expediente acerca del caso planteado y resuelto para archivo, sin embargo algunos Cabildos no tienen un orden y no lo realizan.

El acta debe contener la fecha y motivo de la reunión, el nombre del que cometió el "delito", 10 "No tiene que ser aquél contemplado por las normas nacionales o los tratados internacionales, sino los que han sido propios dentro
del sistema normativo de la comunidad". CRIHU de la Plata Huila (Consejo regional de indigenas del Huila). 
su identificación, los hechos, la investigación realizada - antecedentes: número de llamados de atención (hasta dos llamados), las constancias de lasintervenciones-la familia del acusado, los que acusan, parte que defiende-; la decisión tomada por la asamblea, la firma del gobernador y las de los implicados en los hechos. Desafortunadamente, por más de que el grupo de inevstigación intentó poder escudriñar el contenido de dichas actas, o al menos su forma, no fue posible conocer alguna.

Ante las situaciones que aún no han sobrepasado los límites, se convocan juntas alrededor del fogón en la cocina para orientar a los padres respecto del comportamiento y orientación de los hijos. Hasta los 10 años no se castigan pero se ponen a trabajar y se les recrimina la falta. Los castigos para los delitos más graves van desde el trabajo comunitario hasta el fuete, el cepo o en el peor de los casos el destierro. Estas sanciones son recibidas casi por igual tanto por hombres como por mujeres, sin embargo para estas últimas por su condición menos resistente, el castigo se reduce a la mitad. Se piensa reglamentar sobre las prácticas religiosas o fetichistas como las brujerías, ya que son de una presentación constante este tipo de $\operatorname{casos}^{11}$.

Debe resaltarse en este último comento que el cepo es una práctica que dentro de algunos de los diferentes resguardos -la mayoría de ellos, casi en su totalidad y según la información suministrada por los indígenasya no implementan esta modalidad por la barbarie que representa. De manera general se puede afirmar, que se presentan dos clases de reuniones, las veredales y las reuniones de todos para establecer un sistema de comunicación y decisión.

Las reuniones veredales se hacen para efectos de control social; se encargan de los casos de inspección comunal que solo interesan a segmentos en conflicto al interior de una vereda, en donde por voluntad propia- para negociar un conflicto- o por citación del cabildo-para información de una investigación y sus resultados- se reúne no toda la vereda, sino los familiares de las partes.

Las generales se citan cuando los conflictos involucran partes (personas, familias nucleares) de varias veredas, casos en los que se cita a representantes (segmentarios y cabildos) de toda la parcialidad.

Cuando los casos son especialmente graves, aunque se surtan entre las parentelas de una sola vereda, pueden ser invitadas a la asamblea las "veredas más vecinas". Las funciones de las reuniones intraparcialidad o "reuniones de todos", son las de confrontar los resultados de las investigaciones de los cabildos, complementar u opinar sobre la imputación y las penas. Si hay consenso, se sigue "lo dicho" en la asamblea, sino la impone el gobernador del cabildo, por lo que el consenso no es condición necesaria ni para imputar ni para aplicar la pena. ${ }^{12}$

Para llevar a cabo los juicios al interior del cabildo, tradicionalmente se ha instituido congregar a la comunidad para realizar un juicio consuetudinario oral. En lo que respecta a sus prácticas penales, no existe una articulación ni con la Constitución ni con las leyes ordinarias; se basan en la costumbre únicamente. Un proceso normalmente se inicia con interponer una demanda ante el alcalde no ante el alguacil por no tener experiencia. En primer lugar debe ponerse al tanto a la familia del infractor o autor del delito para que en su seno traten de buscar una posible solución. Esto puede trascender y ser del conocimiento de todas las familias para una posible resolución. Si tampoco nada

11 Entrevista realizada al Guambiano Jairo Embúz por miembros del semillero INTI YACTA USCO.

12 PACHÓN, Ximena. “Guambía”. Introducción en Colombia amerindia. Bogota; ICAN, 1978. Pág. 235-249. 
se logra, se acude al cabildo. El encargado de comentar la situación a todo el cuerpo del cabildo es el secretario. Posteriormente, se inician las investigaciones: fecha y hora del suceso, las partes, los instrumentos, el asunto, la declaración y los testigos.

Aquí se tiene muy en cuenta la sinceridad con que se confiesa y el arrepentimiento por lo cometido, por ello le dan consejos para que no lo vuelva a repetir y lo comprometen a devolver lo que se apoderó y a trabajar un determinado tiempo como enmienda. Dentro de su autonomía, igualmente respetan la de otros resguardos. El propio cabildo es el centro de justicia y conciliación. Lo que primero se trata de hacer es la conciliación. De esta manera se le da trámite a los casos según su gravedad.

Para finalizar el proceso, se levanta un acta y una resolución por escrito que se lee en el cabildo en pleno. Estas fuentes escritas al igual que algunos reglamentos los compila el secretario. En detalle el proceso es el siguiente:

Denuncia presentada por el afectado a través de un oficio donde relata los hechos e indica a sus testigos. Si la situación ha sido detectada por el cabildo, este también puede iniciar la demanda.

Citación o llamamiento por parte del cabildo a los presuntos implicados.

Si los citados por el cabildo no acuden al llamamiento, los alguaciles proceden a buscarlos para hacerlos comparecer.

Al acudir las partes, sobre todo los acusados a la confesión pública, se les pregunta si están en embarazo o con su menstruacióntratándose de mujeres- o si se encuentran enfermos. Esto se realiza, con el objeto de escucharlos dentro de sus capacidades físicas y psicológicas plenamente, o en el caso de recibir el castigo corporal, no vayan a resultar afectados.

Se realiza un careo mediante un ritual conocido con el nombre de cruce de bastones, el cual consiste en que frente al cabildo en pleno, a lado y lado de los bastones de mando que se cruzan, es decir, la confrontación de la palabra del sindicado con la de las personas que rindieron testimonios en su contra.

Si hay necesidad de convocar al Consejo de Taitas dependiendo de la gravedad del asunto, se reúnen los ex gobernadores, quienes conforman tal consejo, en aras de la toma de determinaciones trascendentales para el caso en cuestión.

Aplicación del correctivo: La aplicación del correctivo, castigo o sanción, por su parte, será lo único que podrá restaurar este equilibrio roto. Al ser aplicada públicamente cumple una labor ejemplarizante y preventiva, que busca disuadir a los demás miembros de la comunidad de cometer faltas en el futuro y al acusado de reincidir.

Otorgamiento del perdón: Se busca manifestarle al universo que todo vuelve a estar en paz, que la alteración ha sido "sosegada" y que de nuevo se reinicia el ciclo con la madre tierra.

Reunión de la consejería del Cabildo: En este último evento del proceso, dicha consejería se encarga de realizar una reflexión con el acusado y ya sancionado para que este no reincida en esta $u$ otra falta y para que sirva de ejemplo al resto de la comunidad.

Generalmente debería llevarse un acta o expediente acerca del caso planteado y resuelto, para archivo, sin embargo algunos Cabildos no tienen un orden $y$ no 10 realizan. ${ }^{13}$

Las sanciones o "correctivos" -como ellos prefieren llamarle- por regla general en las comunidades están dados por el trabajo 
comunitario y por la consejería de las autoridades al transgresor, para que este no reincida en ese $\mathrm{u}$ otros comportamientos reprochables por el reglamento interno del cabildo.

Aquellos que son corporales son aplicados en los casos más extremos y cuando se aplican son ejemplarizantes para el resto de la comunidad.

\section{DE LAS INSTITUCIONES:}

Dentro de las instituciones legitimadas y competentes para administrar justicia se encuentran:

1. El cabildo: La reunión de autoridades del cabildo.

2. La Asamblea: Es la comunidad en general, la cual se encuentra conformada por la totalidad de sus comuneros y es dirigida por una junta directiva, donde al momento de tomar alguna decisión deben asistir la mayoría de ellos, teniendo en cuenta que su participación se configura en la "levantada de la mano", lo que se podría interpretar como su voto.

3. El Consejo de taitas o de mayores: Compuesto por los ex gobernadores que no hayan tenido antecedentes de ninguna naturaleza.

4. El Consejo mayor de Guambía: También compuesto por ex gobernadores pero del resguardo del Municipio de Silvia en del Departamento del Cauca. Allí se halla la mayoría de la comunidad guambiana, cuyo impacto o influencia sobre algunos aspectos de los diferentes ámbitos de la vida de la comunidad del Huila, es bastante amplia.

5. La jurisdicción ordinaria: En última instancia y excepcionalmente, siempre y cuando haya un traslado del proceso llevado a cabo en el cabildo por parte de las autoridades competentes.

\section{DE LAS AUTORIDADES POLICIVAS Y SUS FUNCIONES:}

Gobernador: Es la máxima autoridad del resguardo identificado con la Vara de la Justicia, su función es la de representar a sus comuneros ante las máximas autoridades indígenas en sus reuniones, proyectos, firmas de convenios con las diferentes organismos internacionales y nacionales. Su función jurisdiccional es la de valorar las faltas, para que luego la comunidad las imponga.

Vicegobernador: Hace las veces de gobernador principal cuando éste se ausenta o abandona el cargo.

Alcalde: Se encarga de coordinar los grupos de trabajo, e inspecciona la labor que realiza el tesorero.

Corregidor: Se encarga de citar a las reuniones, maneja el orden, hace las veces de policía ordinaria cuando un indígena comete una falta, es él quien notifica por primera vez para que éste se presente ante la junta.

Alguacil: Es la parte policiva, coercitiva y su labor esta encaminada a mantener el orden dentro del resguardo y hacer efectiva la captura cuando el indígena no acata el llamado para corregir su falta.

Tesorero: El encargado de administrar los recursos que le llegan al resguardo provenientes tanto de las actividades propias como venta de sus productos, eventos entre otros y los provenientes del gobierno para salud educación y cultura.

Fiscal: Es el encargado de realizar el control de las funciones del tesorero y los diversos proyectos que se desarrollen dentro de la comunidad.

Secretario: Se encarga de llevar el orden de las reuniones, como leer el acta, verificar 
si hay quórum, llevar los documentos del resguardo y ser un moderador en las reuniones de la junta directiva.

\section{DE LA LEY DE COMPETENCIAS:14}

Dependiendo del lugar de ocurrencia de los hechos y para efectos de determinar la autoridad que deberá conocer del asunto, es necesario tener en cuenta la "LEY DE COMPETENCIAS"。

\section{GENERALMENTE}

1. Cuando la conducta se comete en el mismo resguardo, el competente para conocer y resolver el asunto será el propio cabildo.

2. Cuando la conducta se cometa por un indígena en otro resguardo y posiblemente de otra comunidad, el cabildo que lo captura (no el de su origen regularmente) debe reportar al de origen del capturado mediante un oficio escrito la falta cometida por este, para que entre ambos resuelvan la situación.

3. Cuando la conducta se lleve a cabo en territorio que no es indígena y las autoridades ordinarias encargadas de la administración dejusticia capturen al autor de esta, deben reportar el caso al resguardo al que pertenece, a través de un oficio. Por otro lado el cabildo que lo reconoce como miembro de su comunidad enviará una solicitud de reclamo o de entrega del capturado, a la autoridad que lo haya arrestado, con el fin de establecer bajo su propia responsabilidad y administración de justicia, el correctivo que se le aplicará en la jurisdicción especial. Es posible que la fiscalía entregue también al cabildo, el reporte de la investigación realizada por las circunstancias presentadas para determinadas eventualidades.

4. Cuando el transgresor no es indígena y lleva a cabo una conducta reprochable dentro de territorio nativo, el cabildo lo puede procesar bajo su justicia penal o remitirlo a la jurisdicción ordinaria, con remisión de un expediente, en tratándose de circunstancias peculiares, delicadas, difíciles y trascendentales para la etnia.

5. Una de las situaciones en que la jurisdicción ordinaria es competente de pleno derecho para adelantar los procesos de judicialización contra indígenas es la concerniente al narcotráfico y terrorismo. Hay cabildos que no tienen la experiencia o el conocimiento suficiente para resolver los asuntos que eventualmente se les puedan presentar, para ello acuden a otros con el ánimo de buscar asesoría.

Por lo general, en su jerga no se habla de sanciones ni de castigos o reprimendas, sino más bien de correctivos. En la implementación de tales enmiendas, las fuentes a las que se acuden $\operatorname{son}^{15}$ :

1. Reglamento interno: Lo instituido tradicionalmente.

2. Decisiones del cabildo: Reunión en pleno de las autoridades.

3. Decisiones de la Asamblea: La comunidad en general.

4. Consejo de taitas: Ex gobernadores sin antecedentes de ninguna naturaleza.

5. Asesorías del CRIHU (Consejo Regional Indígena del Huila): Presta asesoría y acude a los procesos, más no tiene decisión.

14 CRIHU (Consejo Regional Indígena del Huila).

15 Guambiano Henry Yalanda vicepresidente del CRIHU (Consejo Regional de indígenas del Huila) Neiva. 
6. Consejo mayor de Guambía: Es fuente auxiliar y está conformado por un consejo de taitas del Cauca, a los cuales se acude cuando se trata de asuntos muy delicados.

7. Asesorías de otros cabildos: Fuente auxiliar.

"La justicia representa el liderazgo, la formación, la prevención y la corrección, esto enmarcado dentro de una Ley de origen que está representada en un todo universal y que ha sido transmitida por nuestros ancestros; es ahí donde verdaderamente se percibe lo que representa la esencia más pura de nuestro pueblo, obviamente adaptándonos a los cambios naturales, espirituales y sociales a los que nos hemos visto sometidos." ${ }^{\prime 16}$

\section{CONCLUSIONES}

La Constitución Política de Colombia de 1991 en su artículo 246, reconoció a los pueblos indígenas a través de sus autoridades, el ejercicio de funciones jurisdiccionales según sus sistemas normativos y procedimientos propios dentro de su ámbito territorial y dejó abierto el campo para reglamentar la articulación entre la jurisdicción especial indígena y el sistema judicial nacional.

En consecuencia, se hace necesario profundizar en el reconocimiento del fuero especial, acopiar experiencias y llegar a unas propuestas de articulación sabia y flexible que le den a aquel, de igual forma, un alcance y contenido necesario. No obstante, tampoco son claras las políticas de la administración ante el nuevo ordenamiento territorial y específicamente frente a los resguardos indígenas; en algunas de las comunidades nativas se percibe un gran desconocimiento de sus derechos y un bajo nivel de organización que dificulta un mejor desarrollo y nivel de vida.

Por otro lado es posible evidenciar el desconocimiento de la administración de justicia de las prácticas penales que tienen los pueblos nativos para poder determinar realmente en que casos se considera pertinente, viable y procedente, elevar la aplicabilidad de la justicia tanto a la jurisdicción ordinaria como a la especial, cuando un caso y consecuencia determinada amerita la asunción respectiva por uno $\mathrm{u}$ otro sistema que aunque disímiles, son reconocidos de manera constitucional, legal y legítima, para darle validez y eficacia a las diferentes actuaciones que ejerzan y que puedan conllevar a una correcta dirección y compatibilidad dentro de la esfera del ordenamiento jurídico.

La reglamentación de la jurisdicción especial indígena tiene que ver con la dotación de instrumentos jurídicos a los cabildos, a las autoridades tradicionales y a los honorables jueces de la República para administrar justicia, pero ante todo, la teleología en tal sentido debe estar relacionada con la idea de una Nación plural en construcción, en referencia a temas como lo público y lo privado, el ámbito de la autonomía estatal y de la autonomía de los pueblos y territorios aborígenes, y los derechos y deberes de los ciudadanos y de las autoridades públicas nacionales y también indígenas.

Es necesario que los intereses de las comunidades étnicas también converjan con las del Estado. Por un lado, el Estado que reconoce a un interlocutor indígena con derechos y por el otro, las organizaciones y comunidades que apelan a él, en aras de su reconocimiento y protección. Ambos deben y buscan beneficiarse de la situación. Primero, las poblaciones indígenas han mostrado su capacidad de movilizarse cuando sus 
intereses fundamentales están en juego y exigen que debe contarse con ellas. Segundo, el Estado que con denodados esfuerzos ha impulsado la capacidad de integrar en su propia acción política y administrativa en aras de contar con la voluntad de los grupos poblacionales étnicos para que participen activamente en las propuestas y para que tomen en sus manos la administración de intereses colectivos.

El fenómeno social y jurídico de las justicias o sistemas especiales, como el caso de la jurisdicción especial indígena es un campo del conocimiento pertinente para la formación integral de los abogados de la Universidad Surcolombiana, en la medida que hace parte del perfil profesional que se busca, según la misión y objetivos expresados en la construcción de la Facultad de Derecho. 